NASA Technical Memorandum 100879

\title{
Experimental Investigation of the Performance of a Supersonic Compressor Cascade
}

\author{
(AASA-TA-100t79) EXPERIMENIAI IAIESTIGALICN \\ CE IEL FEEFCHAACE CF A SUFEFSCNIC \\ CCMEBSSCR CASCALE (AASA) $30 \mathrm{~F}$ CSCL OIA \\ $N 8 y-1 C E 58$

$\begin{array}{ll}\text { inclas } \\ 3302 & 0109398\end{array}$

D.L. Tweedt

Lewis Research Center

Cleveland, Ohio

H.A. Schreiber and H. Starken

Institut für Antriebstechnik

DFVLR

Cologne, Federal Republic of Germany

Prepared for the

33rd International Gas Turbine and Aeroengine Congress and Exposition sponsored by the American Society of Mechanical Engineers

Amsterdam, The Netherlands, June 5-9, 1988 



\title{
EXPERIMENTAL INVESTIGATION OF THE PERFORMANCE OF A
}

\section{SUPERSONIC COMPRESSOR CASCADE}

\author{
D.L. Tweedt \\ National Aeronautics and Space Administration \\ Lewis Research Center \\ Cleveland, Ohio 44135 \\ and \\ H.A. Schreiber and H. Starken \\ Institut für Antriebstechnik \\ DFVLR \\ Postfach 906058 \\ 5000 Cologne 90, Federal Republic of Germany
}

\section{SUMMARY}

Experimental results are presented from an investigation of a linear. supersonic, compressor cascade tested in the supersonic cascade wind tunnel facility at the DFVLR in Cologne, Federal Republic of Germany. The cascade design was derived from the near-tip section of a high-through-flow axial flow compressor rotor with a design relative inlet Mach number of 1.61. The DFVLR cascade blade section coordinates were scaled from an existing design which had been done by the Detroit Diesel Allison Division of the General Motors Corporation.

Test data were obtained over a range of inlet Mach numbers from 1.23 to 1.71 , and a range of static pressure ratios and axial-velocity-density ratios (AVDR) at the design inlet condition. Flow velocity measurements showing the wave pattern in the cascade entrance region were obtained using a laser transit anemometer. From these measurements some unique-incidence conditions were determined, thus relating the supersonic inlet Mach number to the inlet flow direction.

The influence of static pressure ratio and AVDR on the blade passage flow and the blade-element performance is described, and an empirical correlation is used to show the influence of these two parameters on the exit flow angle and total-pressure loss for the design inlet condition. The correlation helped to understand these results because they were affected by a relatively strong coupling of AVDR to static pressure ratio through sidewall boundary-layer effects.

At design point conditions (inlet Mach number $=1.61$, static pressure ratio $=2.15$, AVDR $=1.0$ ) the total-pressure loss coefficient was measured to be 0.143 , with a corresponding flow turning of $-3.4^{\circ}$. An AVDR increase from 1.0 to 1.15 decreased the loss coefficient by about 0.025 with an accompanying increase in flow turning of $3.5^{\circ}$.

\section{INTROOUCTION}

The development of high-speed fanc and compressors operating with supersonic relative inlet Mach numbers requires knowledge of the rotor blade-element 
performance and the flow behavior peculiar to these operating conditions. The linear supersonic compressor cascade can be a useful experimental tool for obtaining some of this information. Although the cascade model has limitations, it can nevertheless provide insight into the relevant flow physics over a wide range of operating conditions with less time and expense than would be required to obtain similar information from an actual rotor. This form of testing allows relatively simple, detailed flow measurement, quickly providing basic information on blade-element loading, losses, and flow turning. Furthermore, when the important aerodynamic boundary conditions are adequately known or controlled, the experimental cascade results are particularly well suited for the assessment and comparison of computational methods.

The purpose of this report is to present and discuss the key results from an experimental investigation of a linear, supersonic, compressor cascade. The cascade design was derived from the near-tip section of a high-through-flow axial flow compressor rotor with a design relative inlet Mach number of 1.61 . The cascade, designated ARL-SL19, was tested in the supersonic cascade wind tunnel facility at the Deutsche Forschungs- und Versuchsanstalt für Luft und Raumfahrt (DFVLR) in Cologne, Federal Republic of Germany. Tests were conducted over a range of inlet Mach numbers from 1.23 to 1.71 with varying static pressure ratios and axial-velocity-density ratios.

The cascade design originated in the early 1970's at the Detroit Diesel Allison (DDA) Division of the General Motors Corporation. The program to design, build, and test this original cascade was sponsored by the Fluid Mechanics Research Laboratories of the Aerospace Research Laboratories (ARL) at Wright-Patterson AFB, Ohio, USA. Results from that program are reported in reference 1 .

For the DFVLR cascade, the blade section coordinates were scaled from the DDA values. However, the blade number and aspect ratio differed between the two studies because of different wing tunnel geometries. A comparison of the DFVLR and DDA cascade results is beyond the scope of this report, but such may be found in a paper by Serovy and Oki ishi (ref. 2).

The scope of the present report is confined to (1) a brief description of the cascade blade design, (2) a description of the DFVLR test facility and instrumentation, and ( 3 ) the presentation and partial analysis of selected results from the DFVLR investigation. Laser anemometer measurements of the cascade inlet flow (unique-incidence) will be discussed. Also, the influence of inlet Mach number on the maximum achievable cascade static pressure ratio and on the cascade total-pressure loss will be examined. And for the design inlet condition, the influence of static pressure ratio (back pressure) and axial-velocity-density ratio (AVDR) on the blade passage flow and blade-element performance will be evaluated. Because the static pressure ratio and AVDR influences were strongly coupled through sidewall boundary-layer effects, a correlation was developed which isolated the effect of each on the cascade performance. This correlation will also be discussed. 
AVDR axial-velocity-density ratio $=\frac{\rho_{2} w_{2}}{\rho_{1} w_{1}} \cdot \frac{\sin \beta_{2}}{\sin \beta_{1}}$

b test section width (blade span)

$d_{\text {max }}$ maximum blade thickness

FU dimensionless tangential blade force

$$
F U=\frac{\left(F_{u} / t\right) / p_{t 1}}{\left(\rho_{1} w_{1}^{2} / p_{t 1}\right) \sin ^{2} \beta_{1}}
$$

$F_{u}$ tangential blade force/unit length

FX dimensionless axial blade force

$$
F X=\frac{\left(F_{x} / t\right) / p_{t 1}}{\left(\rho_{1} w_{1}^{2} / p_{t 1}\right) \sin ^{2} \beta_{1}}
$$

$F_{x}$ axial blade force/unit length

$H$ test section height ( $f i g .4$ )

$\ell$ blade chord length

M Mach number

Mis isentropic Mach number $=f\left(p / p_{t 1}\right)$

p static pressure

pt total pressure

$p_{t 2 n}$ local total pressure at downstream measurement location

$t$ blade pitch

rLE leading-edge radius

$T$ static temperature

w relative flow velocity

B flow angle with respect to cascade front (fig. 1)

Bs stagger angle (fig. 1)

$Y$ ratio of specific heats $=1.40$ for air 
$\eta \quad$ coordinate in tangential direction (fig. 1)

n1 coordinate in tangential direction for laser anemometer measurements in the cascade inlet region ( $f i g .6$ )

$n_{2}$ coordinate in tangential direction for downstream traversing probe measurements ( $f i g .6$ )

$\theta \quad$ dimensionless parameter $=\frac{\text { AVDR }}{\left(p_{2} / p_{1}\right) \tan \beta_{2}}$

$\lambda$ dimensionless parameter $=\frac{\psi_{1} \sin \beta_{1}}{\pi_{1} \cos \beta_{2}} \theta$

$\checkmark \quad$ Prandtl-Meyer angle

$\xi \quad$ coordinate in axial direction ( $f i g .1$ )

$\xi_{1}$ coordinate in axial direction for laser anemometer measurements in the cascade inlet region ( $f i g .6$ )

$\xi_{2}$ coordinate in axial direction for downstream traversing probe measurements ( $\mathrm{fig} .6$ )

$\pi \quad$ static-to-total pressure ratio $=\left(1+\frac{\gamma-1}{2} M^{2}\right)^{-\gamma /(\gamma-1)}$

p density

$\sigma \quad$ blade solidity, chord length/pitch

$\phi \quad$ blade camber angle

$x$ dimensionless axial blade force parameter

$x=1+\left(1+\frac{1}{A V D R}\right)\left(1-\frac{p_{2}}{p_{1}}\right) /\left(2 \gamma M_{1}^{2} \sin ^{2} \beta_{1}\right)$

$\psi \quad$ dimensionless mass-flow parameter

$$
\psi=M\left(1+\frac{\gamma-1}{2} M^{2}\right)^{-(\gamma+1) /(2 \gamma-2)}
$$

$\omega \quad$ total-pressure loss coefficient $=\left(p_{t 1}-p_{t 2}\right) /\left(p_{t 1}-p_{1}\right)$

$\omega_{n} \quad$ local total-pressure loss coefficient $=\left(p_{t l}-p_{t 2 n}\right) /\left(p_{t l}-p_{1}\right)$

Subscripts:

ax axial direction 
LE leading edge

$N$ nozzle exit condition

1 uniform condition far upstream of (infinite) cascade

2 uniform condition far downstream of (infinite) cascade

\section{CASCADE BLACE DESIGN}

The ARL-SL19 supersonic compressor cascade has a design inlet Mach number of 1.61, with a design subsonic axial Mach number component of 0.90 . The design static pressure ratio and axial velocity density ratio (AVDR) are 2.15 and 1.00 , respectively. As discussed in reference 1 , the cascade is a "twodimensional" redesign by DDA of the rotor blade near-tip (streamline 19) section of an ARL- designed high-through-flow compressor (refs. 3 to 4 ). The cascade was intended to represent the two-dimensional aerodynamic equivalent of the rotor blade section. Note that the cascade blade is different from the rotor blade section. The rotor blade section had a positive camber angle of $4.65^{\circ}$ and a stream-tube area contraction of about 11.3 percent at design, whereas the cascade blade has a negative camber angle of $-2.89^{\circ}$ and no streamtube contraction at design. Several of the cascade geometric parameters are listed in table I and shown in figure 1 along with the cascade geometry. A drawing of the cascade blade is shown in figure 2, and the ARL-SL 19 blade coordinates can be found in either reference 1 or 2 .

The design procedure generated airfoils of arbitrary geometry where the camberline was related in a prescribed manner to the desired relative flow angle distribution along the chord (ref. 1). In order to achieve a low-loss cascade, an attempt was made to minimize pressure gradients on the airfoil, especially gradients across shock waves. The so-called precompression airfoil which resulted from this procedure has an "s-shaped" camberline with negative camber in the forward portion ( $f$ ig. 2). The net effect of the blade shape is to reduce the average Mach number at the covered-passage entrance to a value less than the upstream (inlet) Mach number, thereby reducing shock losses, and possibly also viscous losses caused by a shock/boundary-layer interaction.

The approximate wave pattern in the entrance region of the cascade, shown in figure 3, was estimated using simple-wave theory for the design inlet condition. Several local Mach numbers are indicated to give an impression of the magnitudes involved. The left-running bow shocks attenuate rapidly with increasing distance from the leading edge, and extend out in front of the adjacent blades as is characteristic for supersonic relative inflow with a subsonic axial component. A unique feature of the precompression airfoil is the formation of a secondary left-running shock wave which intersects the detached bow shock of the adjacent blade. This so-called precompression shock forms from the coalescence of the left-running characteristics emanating from the concave forward portion of the blade suction surface. Although this compression is relatively weak, it significantly reduces the Mach number of the flow entering the covered passage.

For static pressure ratios at and below the design static pressure ratio, an oblique shock wave runs into the blade passage (fig. 3) where it intersects the suction surface of the adjacent blade at about 75 percent chord. The flow 
incident on this oblique passage shock wave has a minimum Mach number of about 1.53 and a maximum Mach number of about 1.68 near the suction surface.

Bow shock losses were minimized with this cascade airfoil design by the very thin leading edge, which generates only a small detached bow shock wave.

\section{TEST FACILITY AND INSTRUMENTATION}

The supersonic cascade wind tunnel at the DFVLR in Cologne is operated as a continuous running, closed loop test facility with several five-stage centrifugal compressors available for supplying air. These compressors can be operated in series or in parallel depending on the test cell requirements. The wind tunnel is equipped with an adjustable converging-diverging nozzle allowing a continuous variation of the test section Mach number from 1.3 to 2.4. Some general information concerning the wind tunnel is listed in table II, and a cross-sectional drawing of the wind tunnel test section is shown in figure 4 .

For the cascade results discussed here, the wind tunnel was operated with an upstream plenum total pressure in the range 100 to $130 \mathrm{kPa}$ and a total temperature between 300 and $312 \mathrm{~K}$. Blade chord Reynolds numbers were in the range $1.1 \times 10^{6}$ to $1.4 \times 10^{6}$ for cascade inlet Mach numbers between 1.30 and 1.71 . Estimated uncertainties for key dependent variables are tabulated in table III.

For the ARL-SL19 tests, five cascade blades of chord length $85.0 \mathrm{~mm}$ and span $152.4 \mathrm{~mm}$ were installed in the test section, giving an aspect ratio of 1.79. The blades were mounted to plexiglas sidewall windows using cylindrical pins, with two pins on each side of each blade. Tailboards were hinged at the trailing edges of the upper-and lower-most blades, and a throttle was located at the downstream end of each tailboard. The cascade could be rotated in order to set the desired angle, $\beta_{N}$, between the cascade inlet plane and the nozzle exit flow.

The purpose of the tailboard/throttle arrangement was to provide for adjustment to the desired back pressure while simultaneously achieving bladeto-blade flow periodicity downstream of the cascade. The so-called "smooth" tailboard ( $f i g .4$ ) was simply a smooth flat plate, whereas the "slotted" tailboard consisted of a thin, hollow chamber with a slotted flow surface which was intended to allow adjustment of the static pressures at the tailboard surface.

The high static pressure ratios which were desired for this cascade could be achieved only by reducing the adverse effects caused by the sidewall boundary layers. Previous experience with transonic and supersonic cascades had shown that increasing back pressure causes considerable thickening of the sidewall boundary layers, with eventual separation, and that the flow, even at midspan, is strongly influenced. At even relatively moderate static pressure ratios, the periodicity of the cascade flow is destroyed because the downstream pressure information propagates upstream through the sidewall boundary layers in the streamwise direction, instead of in the axial direction. Typically in a supersonic compressor cascade, the supersonic flow in the rearmost passages (fig. 4) becomes unstarted by the high back pressure, while the other passages remain started. In order to reduce these adverse effects and to achieve much higher static pressure ratios across the cascade, sidewall suction was applied 
through slots in the forward part of the blade passages. As shown in figure 5, suction slots were oriented almost perpendicular to the flow direction near the passage-entrance shock wave where most of the pressure rise occurs (ref. 5). The suction system proved to be very effective in stabilizing the sidewall boundary layers at high static pressure ratios, thus allowing the attainment of much higher pressure ratios while maintaining reasonable bladeto-blade flow periodicity. As a second step towards better controlling the cascade flow conditions, two slanted holes were added at the rear of each blade passage (fig. 5). This was done in order to allow removal of more sidewall boundary-layer fluid, thereby providing better regulation of the axialvelocity-density ratio (AVDR).

The wind tunnel was instrumented with wall static pressure taps in the nozzle exit region, in the cascade inlet region $\left(\xi_{1}=8 \mathrm{~mm}\right.$; coordinate system in fig. 6), and in the cascade exit region $\left(\xi_{2}=28 \mathrm{~mm}\right)$. The center blade was instrumented with 10 static pressure taps on its suction surface, and the adjacent blade (above center in fig. 4) with 10 taps on its pressure surface (ref. 6). This encompassed the same flow passage. The total pressure at the cascade inlet, $P_{t l}$, was measured upstream in the plenum. Downstream bladeto-blade measurements of static pressure, total pressure, and flow direction were obtained at midspan by traversing a combination probe (ref. 6) which was located at an axial distance of $26 \mathrm{~mm}\left(\xi_{2} / l_{a x}=0.56 \mathrm{~mm}\right)$ downstream of the cascade exit plane, as indicated in figure $\tilde{b}$. In order to reduce the adverse effects of the probe stem on the transonic exit flow field, the probe was designed with the stem displaced about $100 \mathrm{~mm}$ downstream of the traverse slot in the sidewall as shown in figure 4 .

Several flow velocity measurements were performed in the cascade inlet region using a laser transit anemometer ( $L 2 F$ velocimeter). These measurements were made at midspan in a plane slightly upstream $\left(\xi_{1}=1.54 \mathrm{~mm}\right)$ of the cascade inlet plane (fig. 6).

A Schlieren system was used for practically all tests as a method of checking the flow periodicity and for observing the wave pattern in the cascade. Although the sidewall suction system and static pressure instrumentation severely restricted visual access to the flow field, the use of the Schlieren system was still possible. Also, several unobstructed Schlieren photographs of the cascade flow were taken during initlal testing before the sidewall suction system and instrumentation were installed.

\section{EXPERIMENTAL CONSIDERATIONS}

A peculiarity associated with this type of cascade is that under normal operating conditions the inlet flow is independent of the exit flow conditions, and furthermore, that the inlet flow parameters of Mach number and flow direction (or incidence) are not independent of each other. "Normal operating conditions" here refers to operation where the covered-passage flow is started. The started condition can exist only above a certain minimum upstream Mach number, sometimes referred to as the starting Mach number. For the ARL-SL19 cascade this starting inlet Mach number has been estimated using simple-wave theory and one-dimensional gas dynamics to be around 1.21 . This estimate assumes no spanwise stream-tube contraction between the upstream flow and the passage throat. 
The primary independent flow variables were the inlet Mach number, the static pressure ratio, and the axial-velocity-density ratio (AVDR), all of which strongly influenced the cascade performance. Dependent variables included the exit flow angle, the exit Mach number, and the total-pressure loss coefficient. The inlet flow angle was also a dependent variable, being a function of the inlet Mach number as discussed later under "Cascade Inlet Flow."

The typical procedure for generating test data was to first set the inlet Mach number at a particular value, and then increase the back pressure ( $i . e .$, the cascade static pressure ratio) incrementally from a low static pressure ratio to the maximum that could be achieved while maintaining periodicity. The operating line generated by this procedure will be referred to as a throttle curve.

Ideally it would have been desirable to vary the AVDR independently of the static pressure ratio, e.g., maintain a constant, prescribed AVDR along each throttle curve by controlling the amount of sidewall suction. Experimentally, however, this was not possible or practical due to a strong dependency of AVDR on static pressure ratio. Increasing the back pressure thickens the sidewall boundary layers considerably, causing a corresponding stream-tube contraction at midspan. The application of sidewall suction stabilized the sidewall boundary layers and allowed some variation of the AVDR. However, for most tests in this investigation, an increase in the cascade static pressure ratio was accompanied by an increase in the AVDR.

\section{RESULTS AND DISCUSSION}

The presentation of the ARL-SLI9 cascade results is organized into four main sections. The first two sections are concerned with the cascade inlet flow and the inlet Mach number influence. The third and fourth sections consider -- for the design inlet condition -- the influence of static pressure ratio and AVDR, respectively, on the blade passage flow, the exit flow angle, and the total-pressure loss. Note that all blade-to-blade average quantities presented here were reduced from experimental data by using the "mixed-out" type of integration (ref. 7 ). This type of averaging involves the application of the conservation equations of gas dynamics to a control volume (assuming blade-to-blade periodicity) situated between the downstream measurement plane and far downstream of the cascade where the flow field is prescribed as uniform.

Two sets of unobstructed Schlieren photographs are shown in figures 7 and 8 for inlet Mach numbers of 1.32 and 1.62, respectively. In both figures the cascade back pressure is increasing from top to bottom. Only moderate static pressure ratios could be achleved under these test conditions because the sidewall suction system was not yet installed.

At the inlet Mach number of 1.32 ( $f$ ig. 7) the Schlieren photographs indicate what appears to be nearly a normal shock wave at the covered-passage entrance. However, the shock is not normal (over most of the covered-passage entrance), but oblique, and the cascade is started.

At the inlet Mach number of 1.62 ( $\mathrm{fig} .8$ ), the cascade was generally started. However, static pressures ratios above 1.8 (approximately) caused 
the supersonic flow into the rear-most passages to unstart, destroying the periodicity of the cascade flow. Subsequent application of sidewall boundarylayer suction permitted all passages to start and to attain static pressure ratios as high as 2.47 for the same inlet Mach number of 1.62. Such sidewall suction also greatly reduced secondary-flcw effects.

\section{Cascade Inlet flow}

Supersonic cascade inlet flows with a subsonic axial velocity component involve a dependency of the inlet flow direction on the inlet Mach number. This dependency, often referred to as unique-incidence, is discussed in several references, e.g., Levine (ref. 8), Novak (ref. 9), Starken (ref. 10), Lichtfuss and Starken (ref. 11), and York and Woodard (ref. 12). An approximate twodimensional method developed by Starken (ref. 10) for calculating the uniqueincidence relationship was applied to the ARL-SLI9 cascade geometry. The results of this calculation are shown in figure 9 . The solid curves were calculated by including approximate losses from the leading-edge bow shock waves. Also shown for comparison is the "no-loss" calculation (dashed lines). The bow shock losses can be seen to produce higher inlet flow angles and lower axial Mach numbers, or equivalently lower mass flow rates through the blade row (ref. 13), as a result of the additional blockage over that of the blade leading edges. Notice that the axial component of the inlet Mach number reaches a maximum value of about 0.88 at an inlet Mach number of 1.62 , and that it decreases slightly at higher inlet Mach numbers.

The experimental results included in figure 9 were obtained by pitchwise integration (described below) of laser anemometer data measured near the inlet plane of the cascade. The agreement between measured and predicted values is good, with a measured inlet flow angle of $147.6^{\circ}$ compared to a predicted value of $147.2^{\circ}$ degrees at the near-design inlet Mach number of 1.62 . The measured inlet flow angle thus yields an axial inlet Mach number of about 0.87 at design.

The laser transit anemometer ( $L 2 F$ velocimeter (ref. 14)) measurements of velocity were performed at midspan locations $1.54 \mathrm{~mm}$ axially upstream of the cascade inlet plane. The measurement locations and measured data for the two lower Mach number conditions in figure 9 are shown in figures 10 and 11 . The solid curves for local Mach number and flow angle represent the theoretical solution of a Prandtl-Meyer expansion around the blade leading edge, and the vertical dashed lines indicate the approximate locations where the bow shock waves (and precompression shock in $\mathrm{fig} .10$ ) intersect the measurement plane. It is significant that the Prandtl-Meyer solutions were not fit to the data, but instead were calculated using the nozzle exit conditions:

$$
\beta+\nu=\beta_{N}+\nu_{N}=\text { constant }
$$

The pitchwise integration of the data was done, assuming blade-to-blade periodicity, by applying the equations of motion to a control volume between upstream infinity and the measurement plane (ref. 11).

The theoretical simple-wave results and the experimental results in figures 10 and 11 , are in fairly good agreement indicating that the rotational flow effects, due mostly to the bow shock waves, are relatively small in the 
inlet region of this cascade. This is, however, not surprising considering the small leading-edge radii.

\section{Inlet Mach Number Influence}

The inlet Mach number is the key parameter behind the static pressure rise achievable in supersonic compressor cascade flows, absent the sidewall boundary-layer effects previously discussed. The solid symbols in the upper graph in figure 12 show the maximum static pressure ratios achieved with the ARL-SL19 cascade over the inlet Mach number range 1.23 to 1.72 . The solid line indicates the approximately linear dependence of maximum static pressure ratio on inlet Mach number. The solid line in the lower graph indicates the corresponding total-pressure loss coefficient levels associated with the maximum static pressure ratios.

These results demonstrate a clear trend of increasing maximum static pressure ratio and total-pressure loss with increasing inlet Mach number. A maximum static pressure ratio of 2.47 was obtained at the near-design inlet Mach number of 1.62 , with a total-pressure loss coefficient of 0.130 (AVDR $=1.18$ ). At an inlet Mach number of 1.71 a static pressure ratio of 2.61 was achieved with a 0.161 total-pressure loss coefficient. Based on downstream wake traverse data roughly half of this loss is estimated to be shock loss (ref. 6).

\section{Static Pressure Ratio Influence}

Varying the cascade static pressure ratio -- at a fixed inlet condition -alters the blade passage and cascade exit flow fields, as well as the overall cascade performance. The influence of static pressure ratio on the blade passage flow is shown by examining a typical set of blade isentropic Mach number distributions for moderate (2.12) to high (2.41) static pressure ratios and a nominal inlet Mach number of 1.58 . The AVDR is almost unity in each of these test cases. The Mach number distributions are shown in figures 13(a) through (d) in the upper graphs, where the circles denote suction surface data and the triangles denote pressure surface data. (The lines connecting the data are only approximate and serve mostly to aid in visually separating the two types of data.) Also shown in each figure is the corresponding pitchwise distribution of the local total-pressure loss coefficient as obtained from the downstream probe traverses. The direction of traverse was such that the "left" and the "right" sides of the wake region in each graph correspond to the pressure and suction surface sides of the blade, respectively. Notice the nonzero loss outside of the blade wakes in each case, as this loss increment indicates the approximate level of shock loss. The sketch in each figure shows the approximate shock pattern (solid lines) and boundary-layer behavior (dashed lines) for that condition. These sketches were constructed using Schlieren photographs in conjunction with the blade isentropic Mach number distributions.

The Mach number distribution on the forward portion (leading edge to 40 percent chord) of the suction surface is nearly the same for all pressure ratios in figure 13. This is because the supersonic entrance region is not affected by changes in back pressure. Although it cannot be seen in these graphs, there is actually a fairly strong deceleration along the concave part of the suction surface starting near the leading edge. This was not measured 
since the blades were too thin to allow static pressure instrumentation upstream of the first tap shown.

At the moderate static pressure ratio of 2.12 , the trailing edge oblique shock wave forms a so-called Mach reflection at the pressure surface of the adjacent blade as indicated in the sketch in figure 13(a). It may be possible that this Mach reflection produces a weak boundary-layer separation, with reattachment, on the pressure surface. Increasing the back pressure moves this shock wave forward into the diverging portion of the covered passage, there reducing the shock's strength until it almost disappears (around 35 percent chord on the pressure surface) for the static pressure ratio of 2.41

(fig. 13(d)). Simultaneously, the shock wave system at the covered passage entrance strengthens with increasing back pressure, eventually forming a lambda-shock at the blade suction surface. The lambda-shock is accompanied by full (turbulent) boundary-layer separation on the suction surface (50 to 60 percent chord) as can be partially identified in the pitchwise distributions of local loss coefficient (fig. 13(a) through (d)). Notice that at the moderate pressure ratios (fig. 13(a) and (b)), the wake region is fairly symmetrical and relatively narrow, whereas at the higher pressure ratios (fig. $13(\mathrm{c}$ ) and (d)), the wake region is asymmetrical with a wake signature indicating boundary-layer separation on the suction surface. The loss in the extended right half of the wake region should be thought of as a combination of viscous and shock losses, as it is the result of the lambda-shock system. Details concerning this type of shock system are described by other researchers (refs. 15 to 17).

The general loss behavior apparent from these four test cases (moderate to high static pressure ratios) is that increasing back pressure causes some reduction in the shock loss (note the loss increment between the wakes), but with a corresponding increase in the viscous loss. The increase in viscous loss can be attributed mostly to a change from weak to strong suction surface boundary-layer separation. The overall (mixed-out) loss coefficient reaches a maximum of 0.150 at the static pressure ratio of 2.21 ( $\mathrm{fig} .13(\mathrm{~b})$ ), but decreases significantly to 0.130 at the higher static pressure ratio of 2.41 ( $f$ ig. $13(d)$ ). Notice that the maximum loss is reached somewhere near the condition where a normal shock wave is situated across the exit of the covered passage.

A fairly large number of measurement data for average (mixed-out) exit flow angle and total-pressure loss coefficient are shown against static pressure ratio in figure 14. Inlet Mach numbers vary between 1.57 and 1.64, with a nominal value of 1.61 . The data scatter is due primarily to the concurrent variation of AVDR with back pressure, the two parameters being strongly coupled through sidewall boundary-layer effects. Some degree of scatter may also be attributable to the inlet Mach number variations. By correlating the cascade data in terms of tangential and axial blade forces, an effort was made to separate the influences of AVDR and static pressure ratio. These correlations are described next, and afterwards compared to the figure 14 results.

\section{Correlations}

Blade forces used to correlate the data were obtained by applying the conservation laws of mass, momentum, and energy to the control volume shown in figure 15. This control volume extends from uniform conditions far upstream to 
uniform conditions far downstream of the blade row, and the momentum equations are applied in the axial and tangential directions as indicated by the bladeforce vectors. The control volume is quasi-three-dimensional since it includes the AVDR in the mass and momentum equations (ref. 6). The energy equation in this case reduces to the condition of constant total temperature over the entire flow field, and conservation of mass is equivalent to the definition of the AVDR:

$$
A V D R=\frac{\rho_{2} w_{2} \sin \beta_{2}}{\rho_{1} w_{1} \sin \beta_{1}}
$$

Note that the inlet parameters are fixed at constant values.

A dimensionless form of the tangential momentum equation (eq. 6) leads to the suggestion that the following dimensionless parameters might be useful for correlating the cascade data in terms of the blade forces (ref. 6):

$$
\begin{gathered}
\text { Independent parameter } \theta \triangleq \frac{A V D R}{\tan \beta_{2}} \frac{1}{\left(p_{2} / p_{1}\right)} \\
\text { Tangential blade force } F U \triangleq \frac{\left(F_{U} / t\right) / p_{t 1}}{\left(p_{1} w_{1}^{2} / p_{t 1}\right) \sin ^{2} \beta_{1}}
\end{gathered}
$$

$$
\text { Axial blade force } F X \triangleq \frac{\left(F_{x} / t\right) / p_{t 1}}{\left(p_{1} w_{1}^{2} / p_{t 1}\right) \sin ^{2} \beta_{1}}
$$

The dimensionless form of the tangential momentum equation is as follows:

$$
F U=-\cot \beta_{1}+\left(\frac{T_{2}}{T_{1}}\right) \theta
$$

In this equation, $\beta_{1}$ is treated as a constant and the temperature ratio can be expressed as a function of the dependent parameters $\theta$ and $\beta_{2}$ :

$$
\frac{T_{2}}{T_{1}}=\frac{2+(\gamma-1) M_{1}^{2}}{1+\sqrt{1+2(\gamma-1) \lambda^{2}}}
$$

where

$$
\begin{gathered}
\lambda=\frac{\Psi_{1} \sin \beta_{1}}{\pi_{1} \cos \beta_{2}} \theta \\
\pi_{1}=\left(1+\frac{\gamma-1}{2} M_{1}^{2}\right)^{-\gamma /(\gamma-1)}
\end{gathered}
$$




$$
\psi_{1}=M_{1}\left(1+\frac{\gamma-1}{2} M_{1}^{2}\right)^{-(\gamma+1) /(2 \gamma-2)}
$$

The dependency of $F U$ on $\beta_{2}$ is relatively small, however, so by approximating $\beta_{2}$ as a constant, $\beta_{2}, 0$, the dimensionless tangential force is reduced to a function of $\theta$ only. Furthermore, the functional form is known a priori as is verified by the correlation for an inlet Mach number of 1.61 shown in figure 16 (bottom). Note that the data shown in this figure and in figure 14 are for the same test cases.

Although the above discussion shows the reasoning behind attempting such a correlation, the usefulness of the parameter $\theta$ depends on how well it correlates the axial blade force data (fig. 16 (top)). The correlation is fair. and a second-order curve fit has been used.

These correlation curves now serve as additional constraints to the conservation equations. Again applying conservation of mass, momentum, and energy to the same control volume (fig. 15), parameters such as exit flow angle, exit Mach number, and total-pressure loss coefficient can be determined as functions of the static pressure ratio and AVDR (ref. 6).

Tangential and axial momentum (combined):

$$
\beta_{2}=\arctan \left(\frac{x-F X(\theta)}{\cot \beta_{1}+F U(\theta)}\right)+180^{\circ}
$$

where

$$
x=1+\left(1+\frac{1}{\operatorname{AVDR}}\right)\left(1-\frac{p_{2}}{p_{1}}\right) /\left(2 y M_{1}^{2} \sin ^{2} \beta_{1}\right)
$$

Conservation of mass:

$$
M_{2}=\sqrt{\frac{\sqrt{1+2(y-1) \lambda^{2}}-1}{\gamma-1}}
$$

Definition of loss coefficient:

$$
\omega=\frac{1-\frac{\pi_{1}}{\pi_{2}}\left(\frac{p_{2}}{p_{1}}\right)}{1-\pi_{1}}
$$

where

$$
\pi_{2}=\left(1+\frac{\gamma-1}{2} M_{2}^{2}\right)^{-\gamma /(\gamma-1)}
$$


The calculation of $\beta_{2}$ is iterative, but convergence is rapid. The semiempirical results obtained from this correlation are shown in figures 17 and $18\left(M_{1}=1.61, \beta_{1}=147.8^{\circ}\right)$.

The curves in figure 17 show the near linear dependence of exit Mach number on static pressure ratio. Note that each curve represents a constant AVDR value, and that the increment in AVDR between each curve is 0.05 . The AVDR is seen to have only a small effect on the exit Mach number, the static pressure ratio being clearly the most dominant parameter.

The semi-empirical curves in figure 18 show the variations in exit flow angle and total-pressure loss with static pressure ratio. The dashed lines in this figure indicate conditions where the uniform (mixed-out) exit flow is sonic. A comparison between this figure and figure 14 reveals the usefulness of the correlation in helping to sort out the AVDR effects, al though some caution should be used when applying these curves in a quantitative manner.

It can be seen in figure 18 that along a constant-AVDR curve a maximum exit flow angle exists at near-sonic exit conditions. This effect is well known for flat-plate cascades, e.g. Lichtfuss and Starken (ref. 11) discuss this throttling behavior in more detail. Notice that in throttling the cascade at constant AVDR between a moderately low static pressure ratio (1.4) and a high static pressure ratio (2.5), the exit flow angle (or flow turning) can be expected to vary at most by about $2^{\circ}$ to $3^{\circ}$, and the net change may in some cases be zero. On the other hand, varying the AVDR will be shown (below) to influence flow turning to a larger extent.

The loss-coefficient curves in figure 18 are especially interesting since they were in no way determined using measured loss data. These curves show what the loss coefficient values must be, assuming blade-to-blade periodicity, as determined by the equations of motion using prescribed (or measured) values of static pressure ratio, AVDR, and exit flow angle. In general, the curves show that over the typical range of moderate static pressure ratios ( 1.8 to $2.2)$ the loss coefficient can be expected to be on the order of 0.10 to 0.15 , and that higher AVDR conditions should provide some reduction in the totalpressure loss. This behavior is discussed further in the next section, where measured loss data are compared for different AVDR conditions and a nearly constant static pressure ratio (about 2.17 ).

The measured loss coefficient for the design point $\left\langle M_{1}=1.61, p_{2} / p_{1}=\right.$ 2.15, AVDR $=1.00$ ) was 0.143 , with a corresponding exit flow angle of $151.0^{\circ}$ (flow turning of $-3.4^{\circ}$ ). The semi-empirical curves for an AVDR of 1.0 (fig. 18) indicate a loss coefficient and exit flow angle of $0.155^{\circ}$ and $151.1^{\circ}$, respectively, at the same point.

\section{AVDR Influence}

The AVDR influence on the blade passage flow in terms of the blade isentropic Mach number distribution is shown in figure 19 for a nominal inlet Mach number of $1.58\left(\beta_{1}=147.9^{\circ}\right)$. The cascade static pressure ratio is nearly constant for the four data sets shown in this figure, although it should be noted that even the small variations in static pressure ratio contribute to and slightly exaggerate the observed trends. 
The main effect of increasing AVDR is a moderate upstream shifting of the rear passage shock waves (see Mis distribution) and a slight steepening of the oblique shock waves at the passage entrance as indicated in the sketch in figure 19. The increased spanwise stream-tube convergence tends to lower the Mach numbers in the passage, thereby reducing the shock loss and the losses from the shock/boundary-layer interaction region. As the tabulated data in figure 19 show, an increase in the AVDR from 1.00 to $1.14\left(p_{2} / p_{1}=2.15\right.$ to 2.22$)$ corresponded to a decrease in the loss coefficient from 0.143 to 0.117 . Also notice the relatively large decrease of $3.3^{\circ}$ in the exit flow angle (increase in flow turning, $\beta_{1}-\beta_{2}$ ).

The cascade performance data plotted against static pressure ratio in figure 14 are shown against AVDR in figure 20. Again, most of the data scatter is due to the concurrent variation of static pressure ratio and AVDR. In order to sort out the AVDR influence, the semi-empirical information contained in figure 18 has been rearranged and graphed against AVDR in figure 21 . In this case each curve represents a constant static pressure ratio as indicated.

The influence of AVDR on total-pressure loss for moderate to high static pressure ratios is, as discussed, that an increase in AVDR causes a reduction in loss. The extent of loss reduction, however, depends on the level of static pressure, with the loss reduction being more pronounced at higher static pressure ratios. Near the design inlet Mach number (1.61) and static pressure ratio (2.15), increasing the AVDR from 1.0 to 1.15 decreased the measured loss coefficient by about 0.025 . The semi-empirical curves in figure 21 show the same decrease.

At low to moderate static pressure ratios (1.4 to 1.6) an increase in AVDR appears to cause an increase in total-pressure loss (figs. 18 and 21 (top)). Since sonic exit conditions occur around a static pressure ratio of 2.0 to 2.1 , it is apparent that this indicated behavior is associated with supersonic exit flow, i.e., wholly supersonic flow throughout the cascade. Conversely, the trend of decreasing loss with increasing AVDR can be associated with sonic to subsonic cascade exit conditions. It is important to note that the curves for conditions of low static pressure and AVDR greater than unity are, at best, uncertain, and that they may even be wrong. The curves for these conditions are only an extrapolation from the measured data, i.e., the correlation contains no data for these conditions.

The influence of increasing AVDR on the exit flow angle (fig. 21 ) is to always reduce it and thereby increase the flow turning. Near the design inlet Mach number (1.61) and static pressure ratio (2.15), increasing the AVDR from 1.0 to 1.15 decreased the measured exit flow angle (increased the flow turning) by about $3.5^{\circ}$. The qualitative physical explanation for this effect is as follows: maintaining a constant static pressure ratio requires that the effective exit flow area remain the same. The increased spanwise stream-tube contraction for a higher AVDR necessitates that the exit flow turn to smaller values of $B_{2}$ (since $\beta_{2}$ is always greater than $90^{\circ}$ for this cascade). Notice that this effect appears to be stronger at the lower static pressure ratios where the exit flow is supersonic.

A comparison of the relative influence of AVDR and static pressure ratio on the exit flow angle yields an interesting conclusion, namely, that the AVDR influence is more dominant. 


\section{SUMMARY OF RESULTS}

Experimental results from an investigation of a linear, supersonic, compressor cascade, tested in the supersonic cascade wind tunnel facility at the DFVLR in Cologne, Federal Republic of Germany, have been presented and discussed. The cascade, with design relative inlet Mach number 1.61, was tested over a range of inlet Mach numbers (1.23 to 1.71), static pressure ratios, and axial-velocity-density ratios (AVDR).

The following principle results were obtained:

1. Flow velocity measurements were obtained in the cascade entrance region using a laser transit anemometer. From these measurements, some uniqueincidence conditions were determined. For the inlet Mach number of 1.62 , the experimental inlet flow angle was found to be $147.6^{\circ}$, giving an axial Mach number of 0.87 . This inlet condition is generally independent of the cascade static pressure ratio and AVDR.

2. Exit flow angle and total-pressure loss data for the cascade at the design inlet condition exhibited considerable scatter due to the relatively strong influence of static pressure ratio on AVDR. The correlation discussed in this report was fairly successful in isolating the influences of these two independent parameters in order to determine their relative effect on exit flow angle (flow turning) and total-pressure loss.

3. At the design point (inlet Mach number $=1.61$, static pressure ratio $=$ 2.15, AVDR $=1.0$ ), the measured total-pressure loss coefficient was 0.143 , with a corresponding exit flow angle of $151.0^{\circ}$ (flow turning of $-3.4^{\circ}$ ).

4. Increasing the AVDR from 1.0 to 1.15 while maintaining all other independent parameters at design values decreased the loss coefficient by about 0.025 , with an accompanying decrease in the exit flow angle (increase in flow turning) of about $3.5^{\circ}$.

5. The maximum cascade static pressure ratio that could be achieved was determined primarily by the inlet Mach number level. A nearly linear dependency of maximum static pressure ratio on inlet Mach number was observed over the range of inlet Mach numbers tested (1.23 to 1.71). At the design inlet condition a maximum static pressure of about 2.47 was achieved. At this operating point, the cascade was observed to have a strong lambda-shock system slightly downstream of the covered-passage entrance. The measured totalpressure loss coefficient for this condition $\left(M_{1}=1.61, p_{2} / p_{1}=2.47\right.$, AVDR $=$ 1.18 ) was 0.130 , with an exit flow angle of $145.6^{\circ}$.

\section{REFERENCES}

1. Fleeter, S., Holtman, R.L., McClure, R.B., Sinnet, G.T., 1975, "Experimental Investigation of a Supersonic Compressor Cascade," ARL-TR-75-0208, Aerospace Research Laboratories, Wright-Patterson AFB, OH.

2. Serovy, G.K., and OKi ishi, T.H., 1988, "Performance of a Compressor Cascade Configuration with Supersonic Entrance Flow -- A Review and Comparison of Experiments in Three Installations," ASME Paper 88-GT-211. 
3. Wennerstrom, A.J., 1983, "The Design and Evaluation of a High-Through-Flow Transonic Axial Compressor, "6th International Symposium on Air Breathing Engines, Paris.

4. Wennerstrom, A.J., and Frost, G.R., 1976, "Design of a $1500 \mathrm{ft} / \mathrm{sec}$, Transonic, High-Through-Flow, Single-Stage Axial Flow Compressor with Low Hub/ Tip Ratio", AFAPL-TR-76-59, Air Force Aero-Propulsion Lab/TB, WrightPatterson AFB, OH. (Avail. NTIS, AD-BO16386L.)

5. Leynaert, J., 1976, "Cascade Test Methods in Wind Tunnel at ONERA," Measuring Techniques in Transonic and Supersonic Cascades and Turbomachines, A. Bolcs and T. Fransson, eds., Juris-Verlag, Zurich, pp. 103-116.

6. Schreiber, H.A., and Tweedt, D.L., 1987, "Experimental Investigation and Analysis of the Supersonic Compresso- Cascade ARL-2DPC, "DFVLR IB-325-02-87, Deutsche Forschungs- und Versuchsanstalt für Luft und Raumfahrt.

7. Schimming, P., and Starken, H., 1975, "Data Reduction of Two-Dimensional Cascade Measurements," Modern Methods of Testing Rotating Components of Turbomachines (Instrumentation), AGARDograph 207, M. Pianko, ed., AGARD, Paris, France, pp. 14-19.

8. Levine, P., 1957, "Two-Dimensional Inflow Conditions for a Supersonic Compressor with Curved Blades," Journal of Applied Mechanics, Vol. 24, No. 2 , pp. 165-169.

9. Novak, O., 1967, "Flow in the Entrance Region of a Supersonic Cascade," Strojnicky Casopis, Vol. 19, C.203, pp. 138-150. (Slovenskej Akademic vied Bratislava.)

10. Starken, H., 1971, "Untersuchung der Strömung in ebenen Uberschallverzögerungsgittern," DLR-FB 71-99.

11. Lichtfuss, H.J., and Starken, H., 1974, "Supersonic Cascade Flow," Progress in Aerospace Science, Vol. 15, D. Kuchemann, ed., Pergamon Press Ltd., New York, pp. 37-149.

12. York, R.E., and Woodard, H.S., 1976, "Supersonic Compressor Cascade -- An Analysis of the Entrance Region Flow Field Containing Detached Shock Waves," Journal of Engineering for Power, Vol. 98, No. 2, pp. 247-257.

13. Starken, H., Zhong, Y., and Schreiber, H.A., 1984, "Mass Flow Limitation of Supersonic Blade Rows Due to Leacing Edge Blockage," ASME Paper 84-GT-233.

14. Schod1, R., 1980, "A Laser-Two-Focus (L2F) Velocimeter for Automatic Flow Vector Measurements in the Rotating Components of Turbomachines," Journal of Fluids Engineering, Vol. 102, No. 4, pp. 412-419.

15. East, L.F., 1976, "The Application of a Laser Anemometer to the Investigation of Shock Wave/Boundary Layer Interactions," RAE Tech. Memo, AERO 1666, see also AGARD-CP-193, Feb. 1976. 
16. Delery, J., Marvin, J.G., and Reshotko, E., 1986, "Shock-Wave BoundaryLayer Interactions," AGARD AG-280, AGARD, Neuilly-Sur-Seine, France.

17. Schreiber, H.A., 1986, "Experimental Investigations on Shock Losses of Transonic and Supersonic Compressor Cascades," Transonic and Supersonic Phenomena in Turbomachines, AGARD-CP-401, AGARD, Neuilly-Sur-Seine, France, pp. 11-1 to 11-15.

TABLE I. - CASCADE GEOMETRY

\begin{tabular}{|c|}
\hline 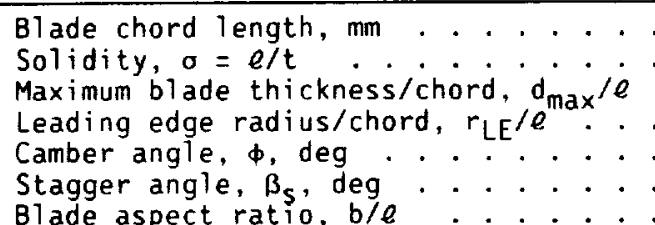 \\
\hline
\end{tabular}

TABLE II. - SUPERSONIC CASCADE WIND TUNNEL

Continuous, closed-loop operation

Total pressure, $\mathrm{kPa}$.......... 30 to 250

Total temperature, K........... 295 to 325

Mach number (variable nozzle) . . . . . . . . 1.3 to 2.4

Test section

Height, H, mm ............... . 238

Width, b, mm .................. 152.4

TABLE III. - ESTIMATED UNCERTAINTIES

(95 PERCENT CONFIDENCE)

\begin{tabular}{|c|c|}
\hline Quantity & Uncertainty \\
\hline Inlet flow angle, $\beta_{1}$ & $a_{ \pm 0.5^{\circ}}$ \\
Exit flow angle, $\beta_{2}$ & $a_{ \pm 0.010}^{\circ}$ \\
Loss coefficient, $\omega$ & ${ }^{\circ} .010$ \\
\hline
\end{tabular}

a These relatively large uncertainties are rough estimates which include an added uncertainty from the effects of nonperiodicity and secondary

flows. 


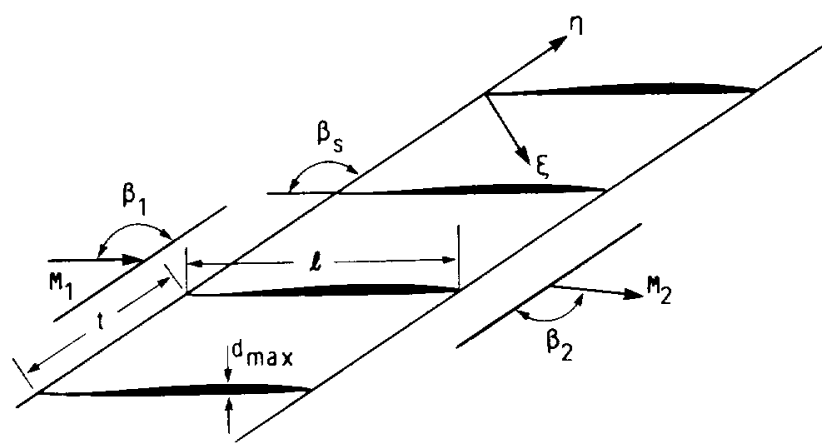

figure 1. - CASCADE geOMEtric Parameters.

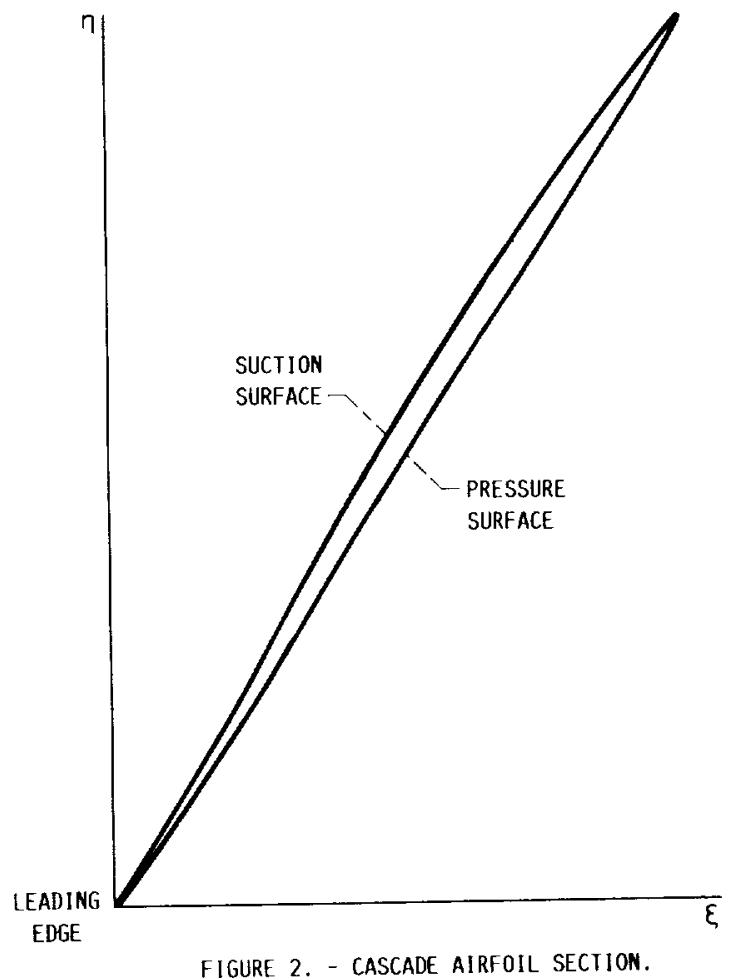

FIGURE 2. - CASCADE AIRFOIL SECTION.

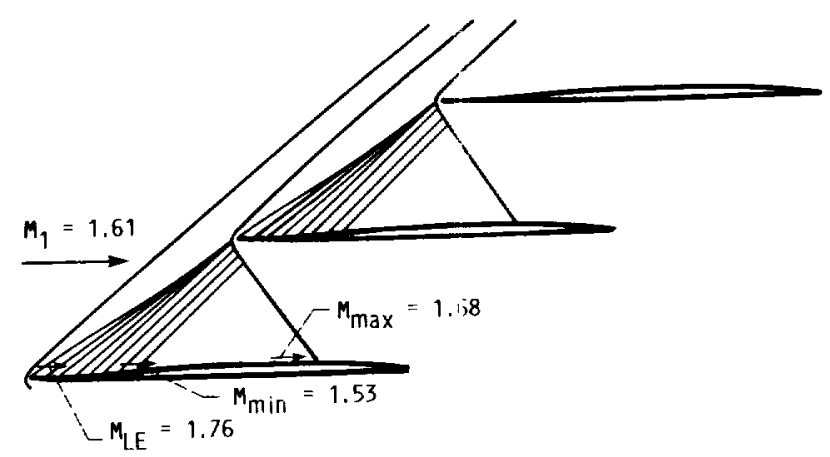

FiguRE 3. - APPROXIMATE INLET WAVE VATTERN AT THE DESIGN INLET FLOW CONDITION. 


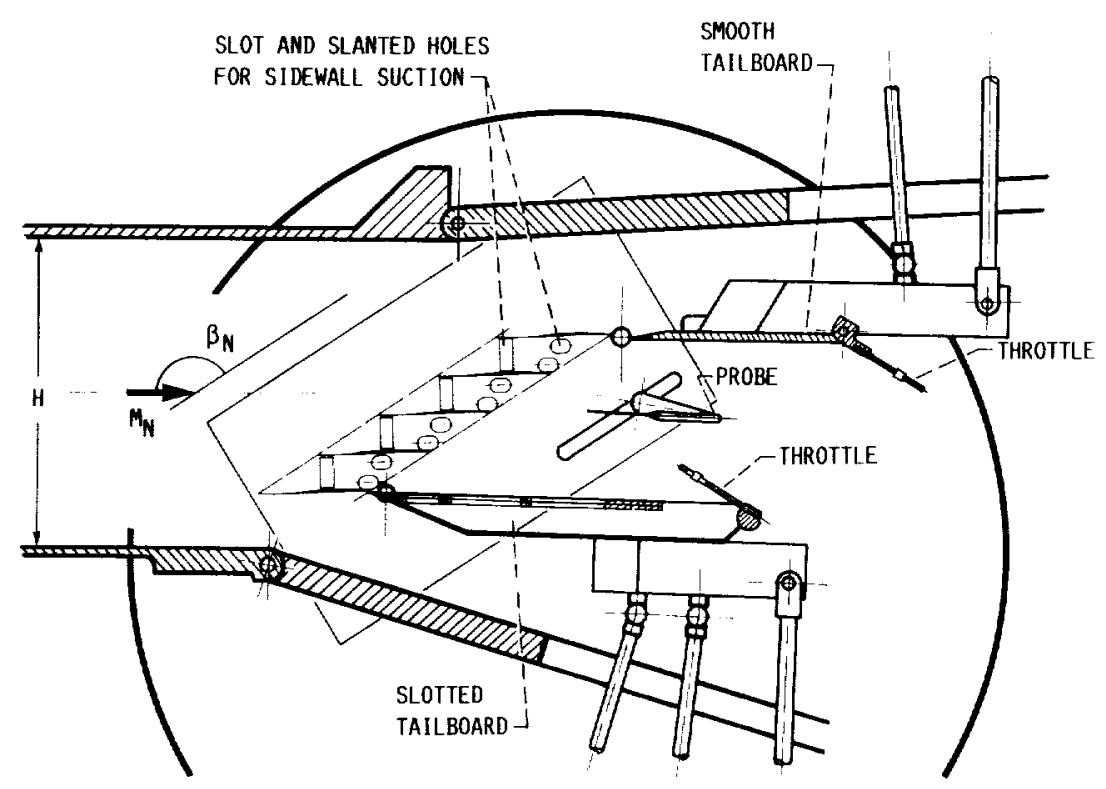

FIGURE 4. - WIND TUNAEL TEST SECTION.

SECTION A-A

BLADE PASSAGE FLOW
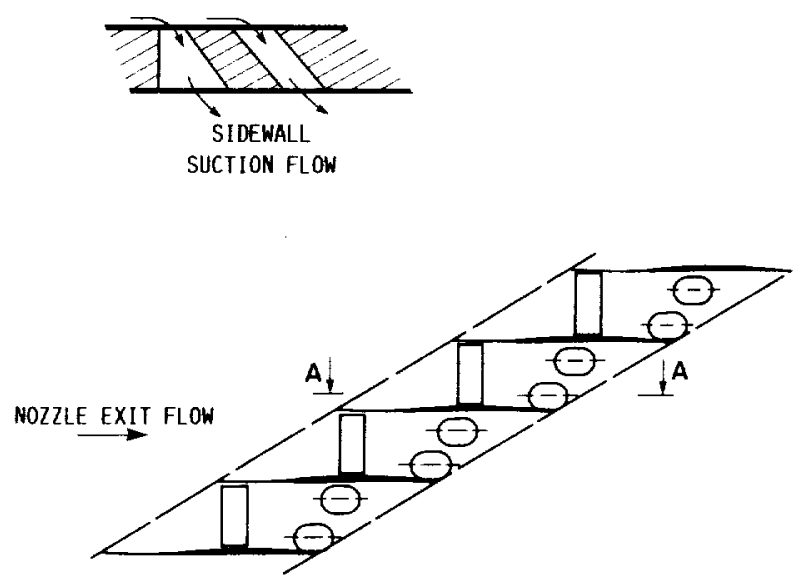

FIGURE 5. - SLOTS AND HOLES FOR SIDEWALL SUCTION.

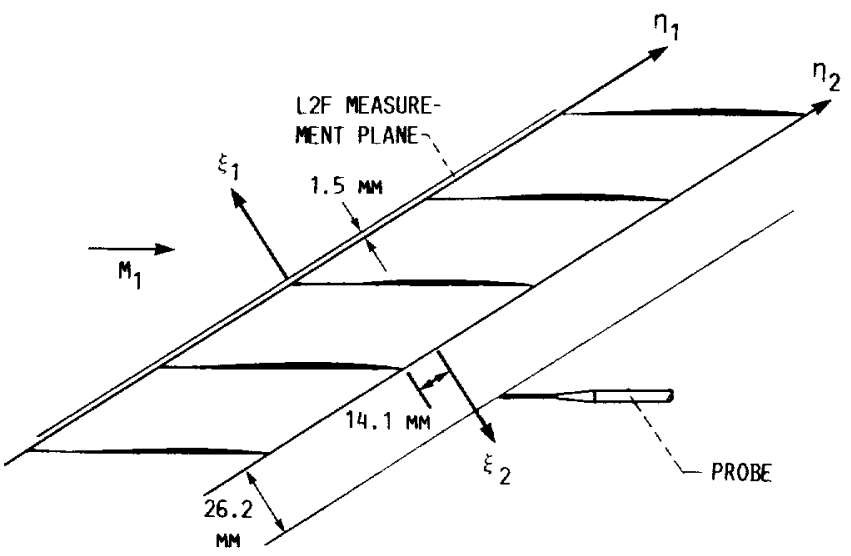

FIGURE 6, - COORDINATE SYSTEMS AND MEASUREMENT PLANES UPSTREAM AND DOWNSTREAM OF THE CASCADE. 


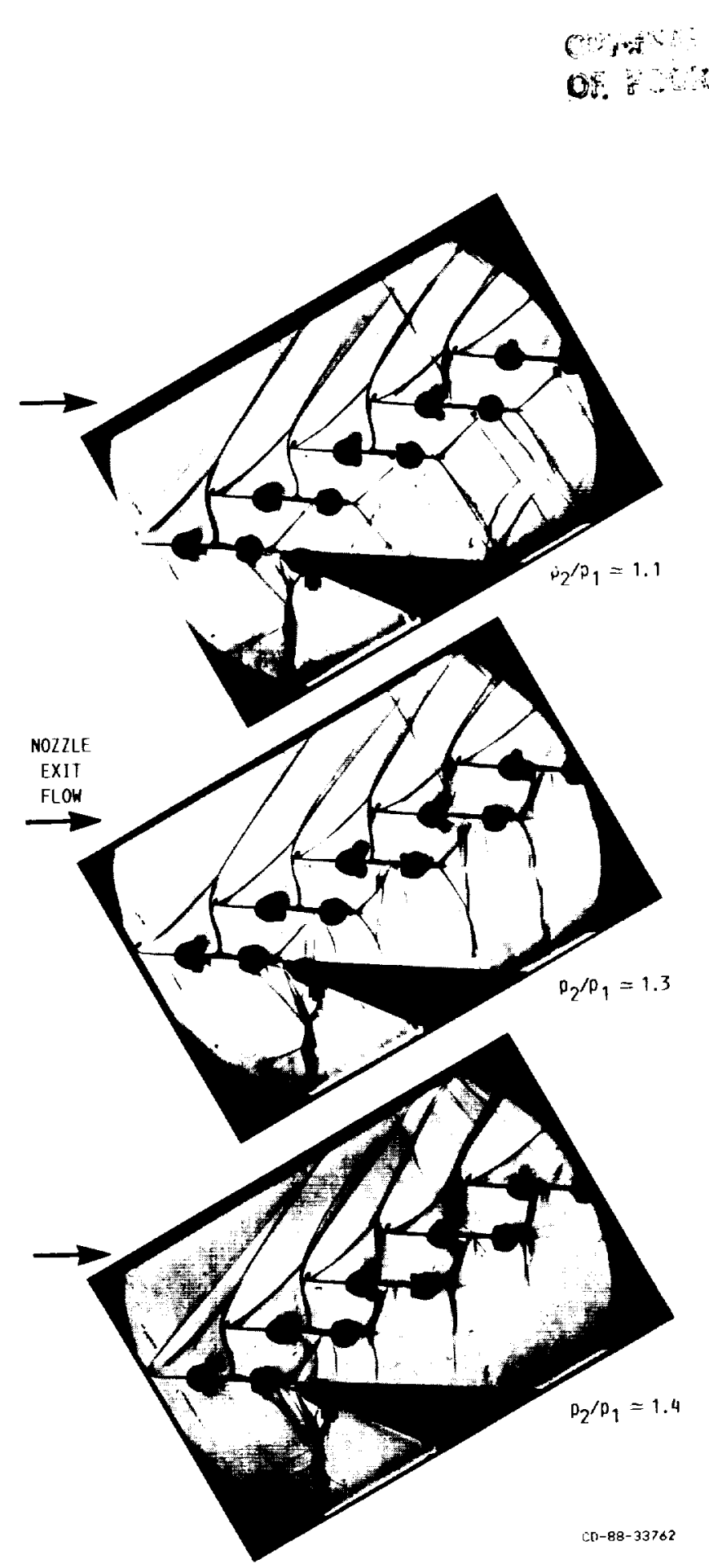

FIGURE 7 - SCHLIEREN PHOTOGRAPHS OF THE. CASCADE FLOW FOR

$M_{1}=1.32$ AND DIFFERENT STATIC PRESSURL. RATIOS (BACK PRESSURES).

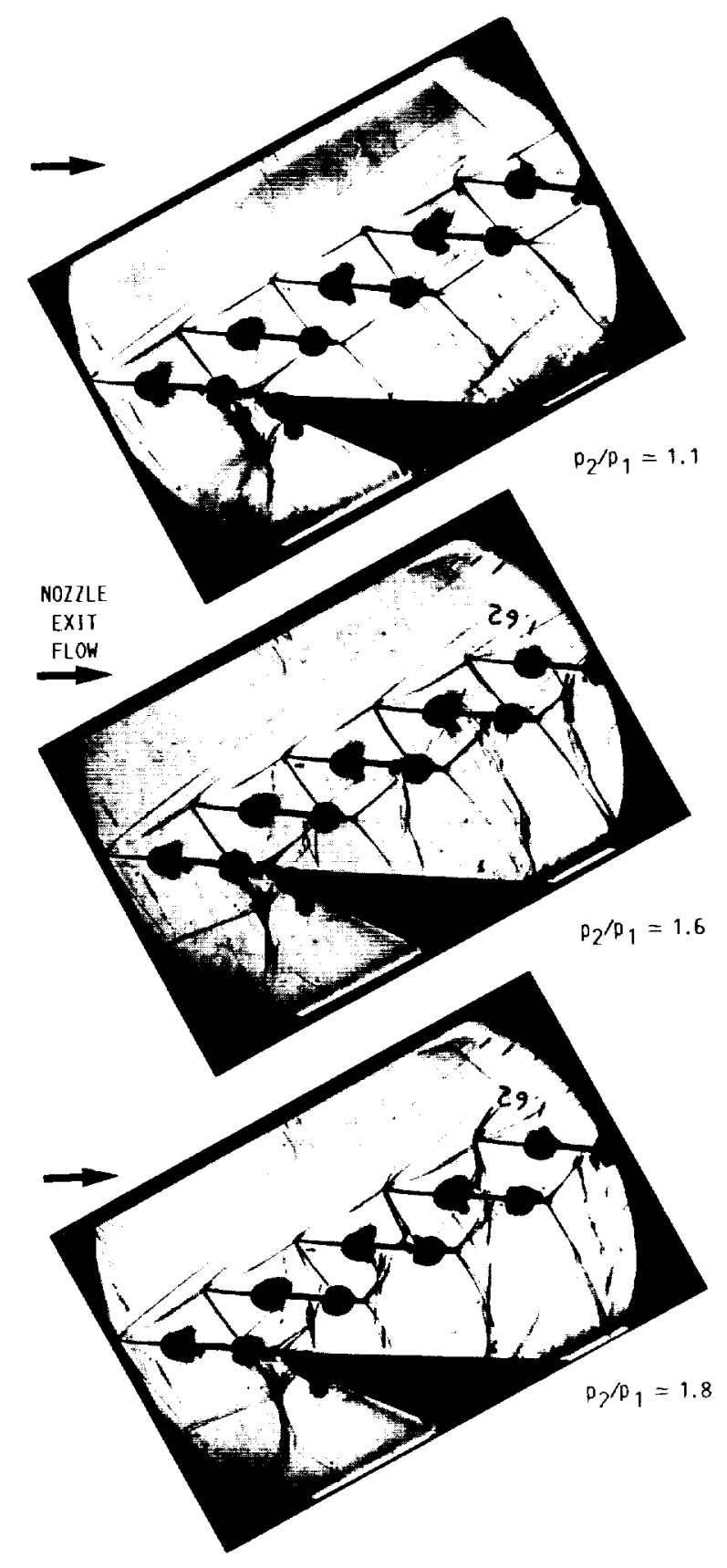

FIGURE 8. - SCHLIEREN PHOIOGRAPHS OF THE CASCADE FLOW HOR $M_{1}=1.62$ AND DIFFERENI STATIC PRESSURE RAI IOS (BACK PRISSURES). 

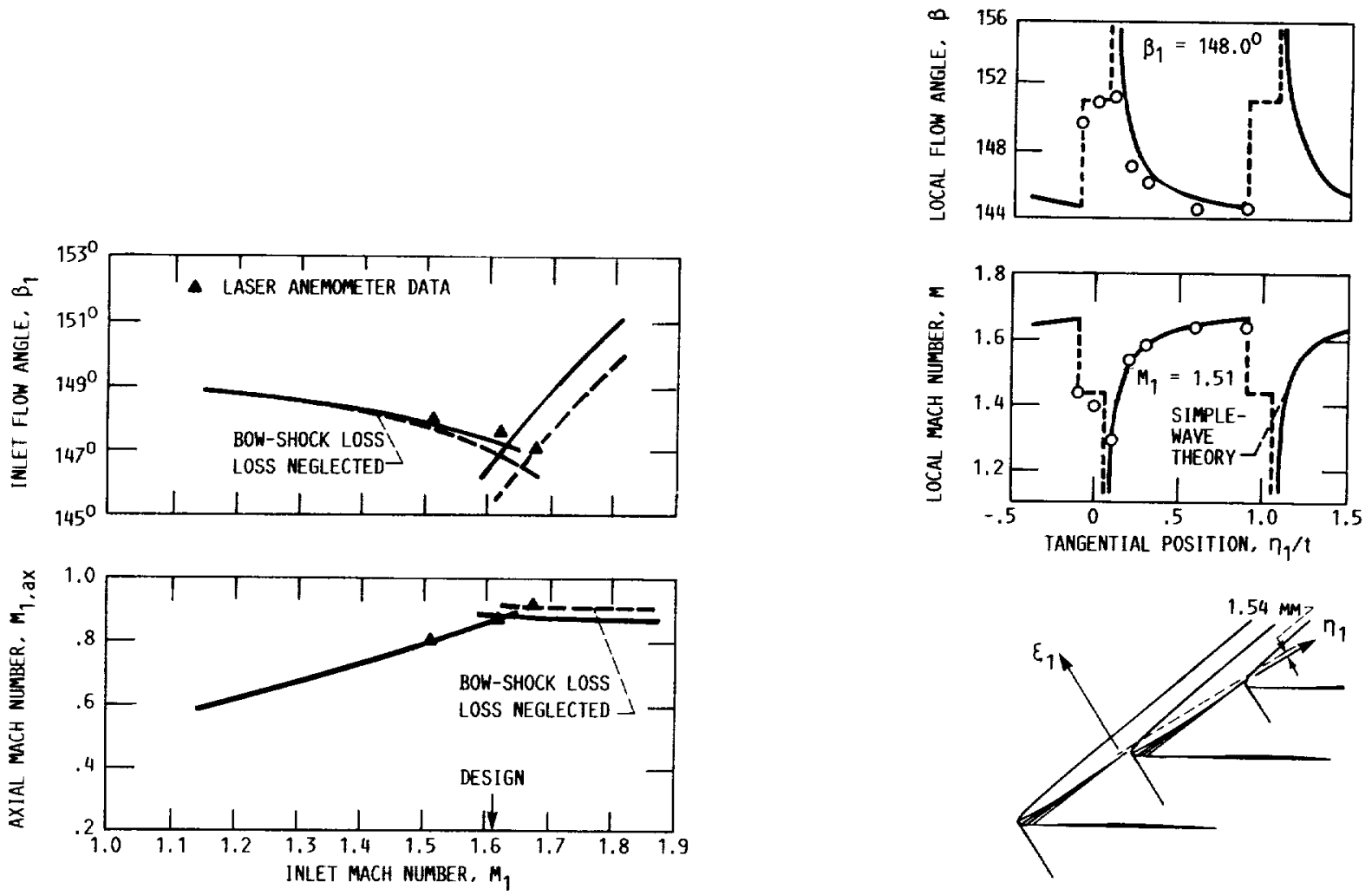

FIGURE 9. - THEORETICAL AND EXPER IMENTAL UNIQUE INCIDENCE CURVES COMPARED WITH LASER ANEMOMETER DATA.

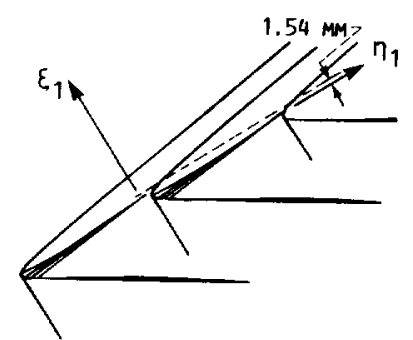

FIGURE 10 , - LASER ANEMOMETER DATA AND MEASUREMENT LOCATIONS (MIDSPAN, $\varepsilon_{1}=$ $1.54 \mathrm{MM}$ ) FOR $M_{1}=1.51$ : COMPARISONS WITH SIMPLEWAVE THEORY. 

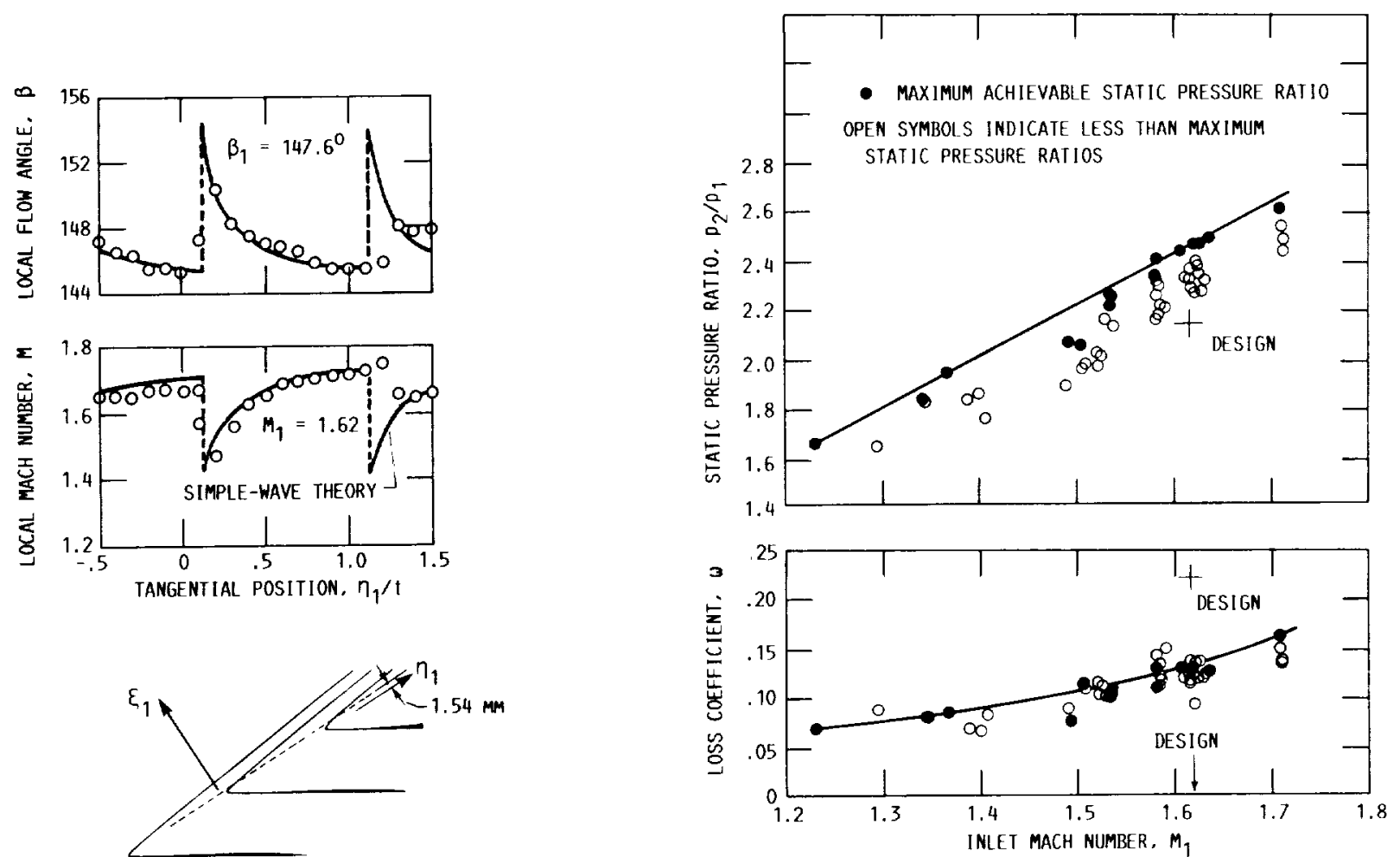

FIGURE 11. - LASER ANEMOMETER DATA AND MEASUREMENT LOCATIONS (MIDSPAN, $\varepsilon_{1}=$

$1.54 \mathrm{MM}$ ) FOR $M_{1}=1.62$ :

COMPARISONS WITH SIMPLE-

WAVE THEORY.

FIGURE 12. - INFLUENCE OF INLET MACH NUMBER ON MAXIMUM ACHIEVABLE STATIC PRESSURE RATIO AND CORRESPONDING TOTAL-PRESSURE LOSS COEFFICIENT. 
NOMINAL $M_{1}=1.58$
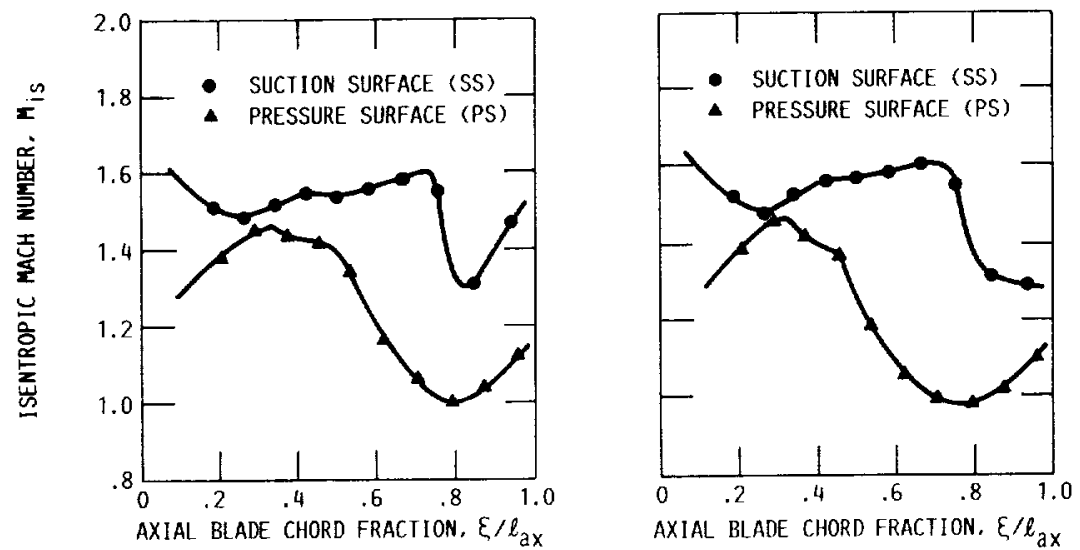

AXIAL BLADE CHORD FRACTION. $\xi / \ell_{\mathrm{ax}}$
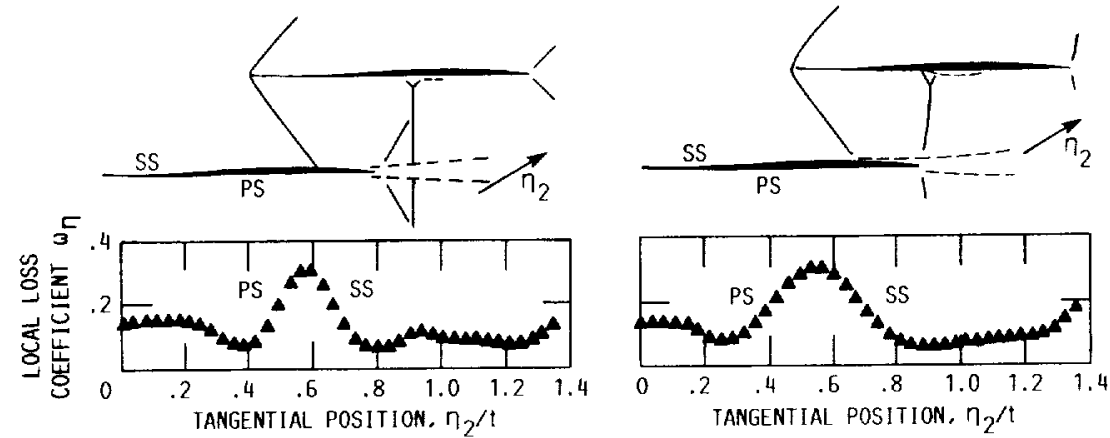

(A) STATIC PRESSURE RATIO $p_{2} / p_{1}=2.12$;

(B) STATIC PRESSURE RAT10 $p_{2} / p_{1}=2,21$; $A V D R=0.99: \beta_{2}=151.2^{\circ}: \omega=0.144$. AVDR $=1.02 ; \beta_{2}=150.2^{\circ} ; 0=0.150$.

FIGURE 13. - INFLUENCE OF STATIC PRESSURE RATIO ON BLADE ISENTROPIC MACH NUMBER DISTRIBUTION FOR A NOMINAL INLET MACH NUMBER OF $1.58\left(\beta_{1}=147.9^{\circ}\right)$ WITH CORRESPONDING BLADE-TO-BLADE LOSSES MEASURED DOWNSTREAM AND SKETCHES ILLUSTRATING APPROXIMATE WAVE PATTERN. 

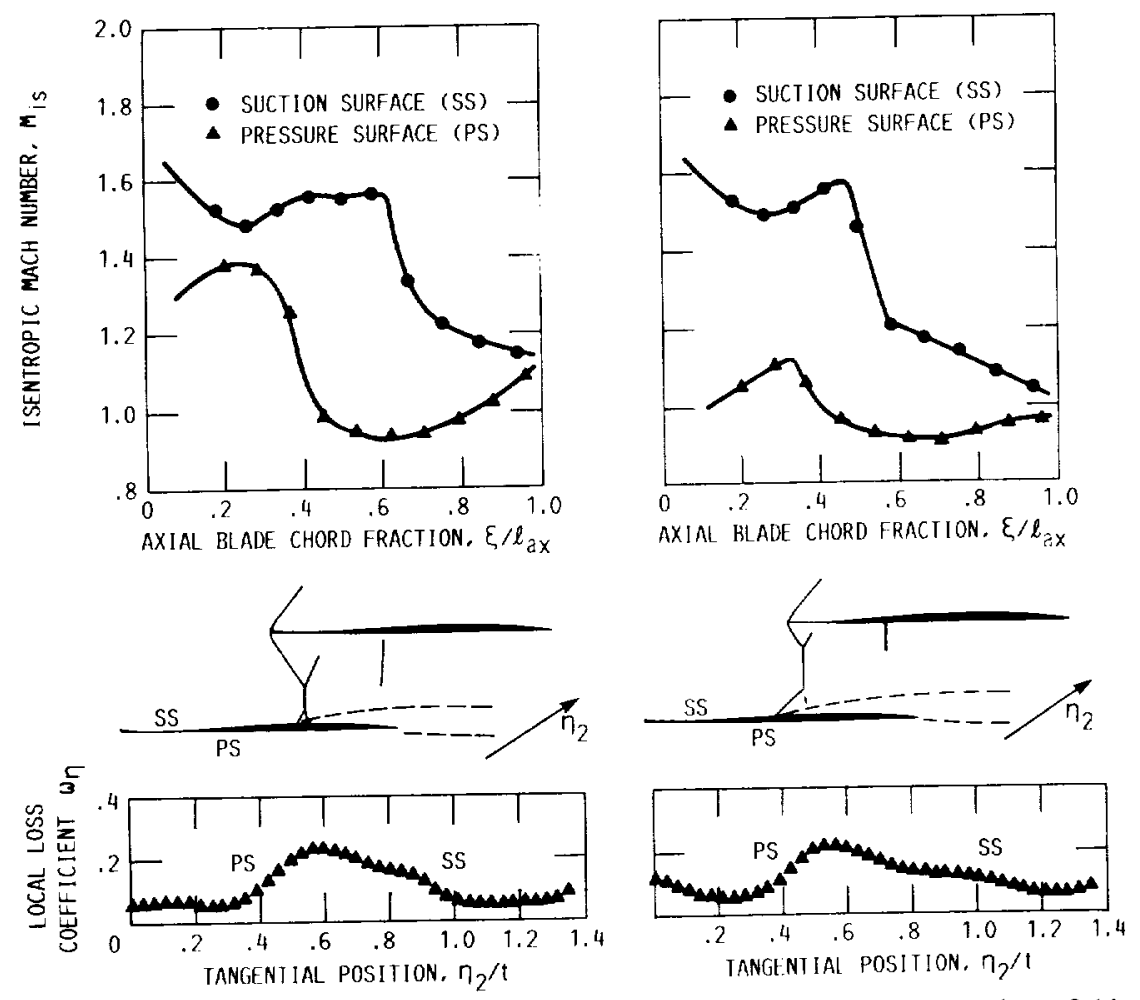

(C) STATIC PRESSURE RATIO $p_{2} / p_{1}=2.30$ : AVDR $=1.07: \beta_{2}=148.8^{\circ} ; \mathfrak{\omega}=0.134$.

(D) STATIC PRESSURE RATIO $p_{2} / p_{1}=2.41$ :

AVDR $=1.06 ; \beta_{2}=148.6^{\circ} ; \omega=0.130$.

FIGURE 13. - CONCLUDED.
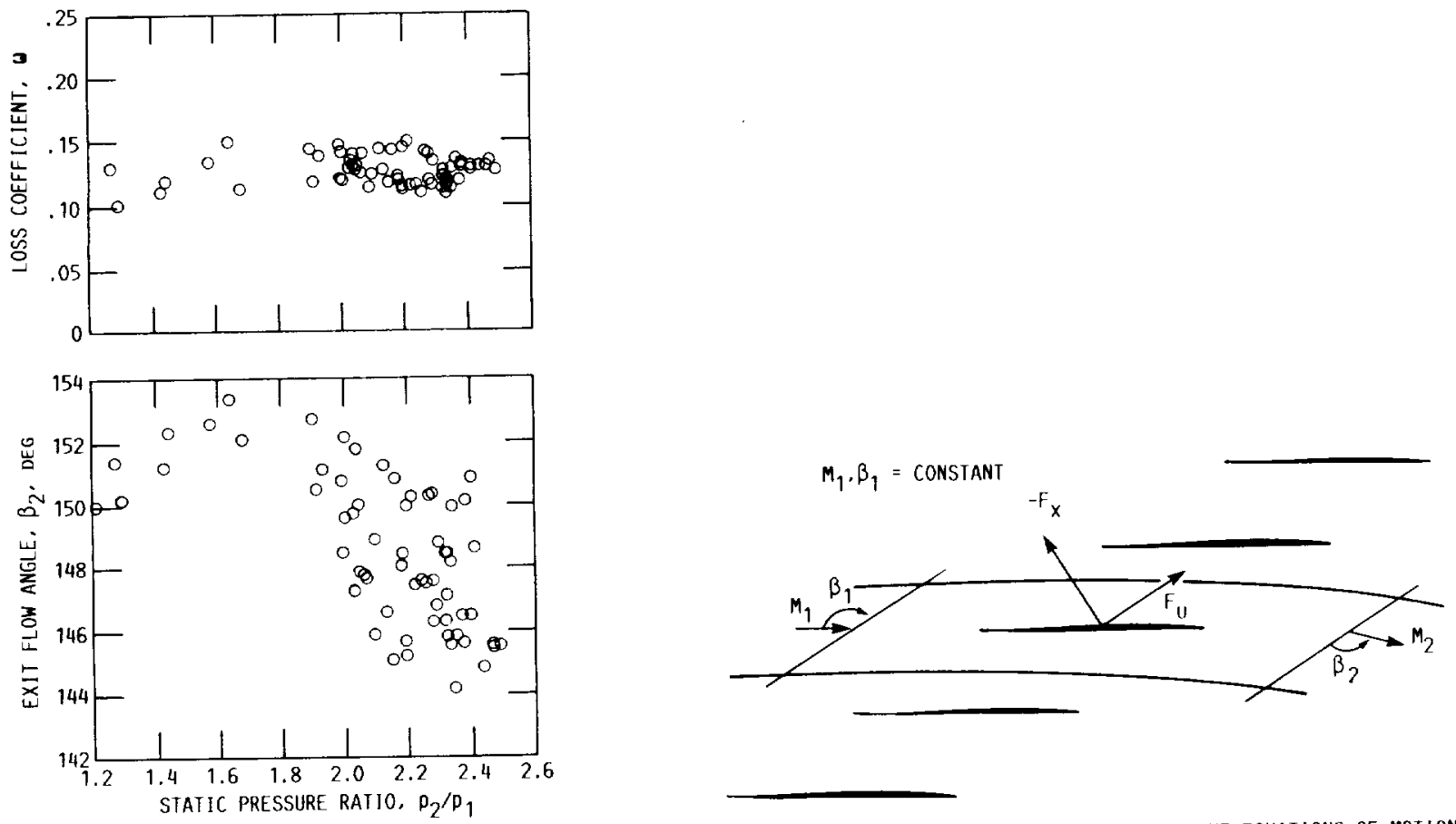

FIGURE 14 . - EXPERIMENTAL DATA FOR INLET MACH NUMBERS RANGING FROM 1.57 TO 1.64 SHOWING THE INFLUENCE OF STATIC PRESSURE RATIO ON THE TOTAL-PRESSURE LOSS COEFFICIENT AND THE EXIT FLOW ANGLE.

FIGURE 15. - CONTROL VOLUME USED TO WRITE THE EQUATIONS OF MOTION FOR THE CASCADE FLOH. 

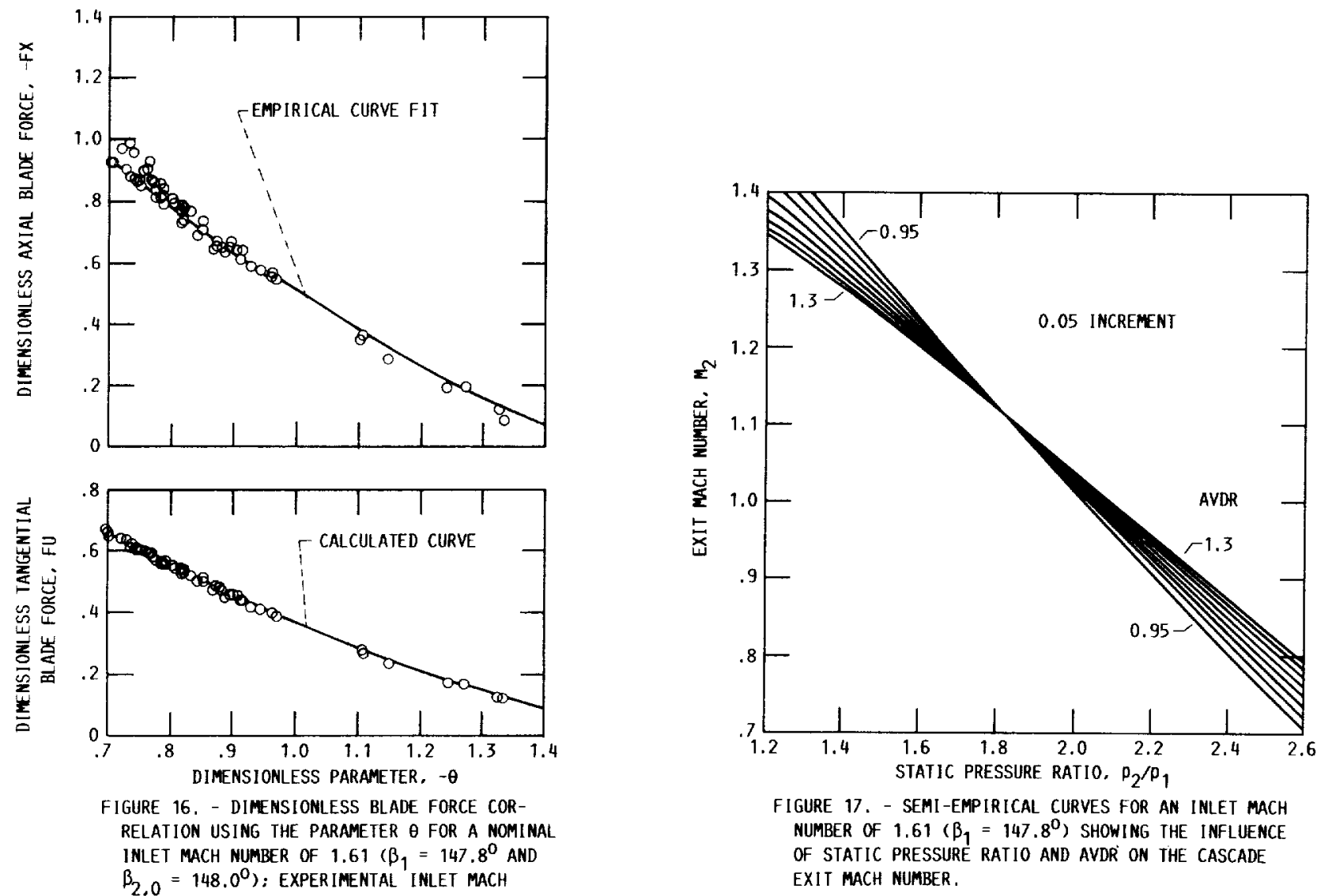

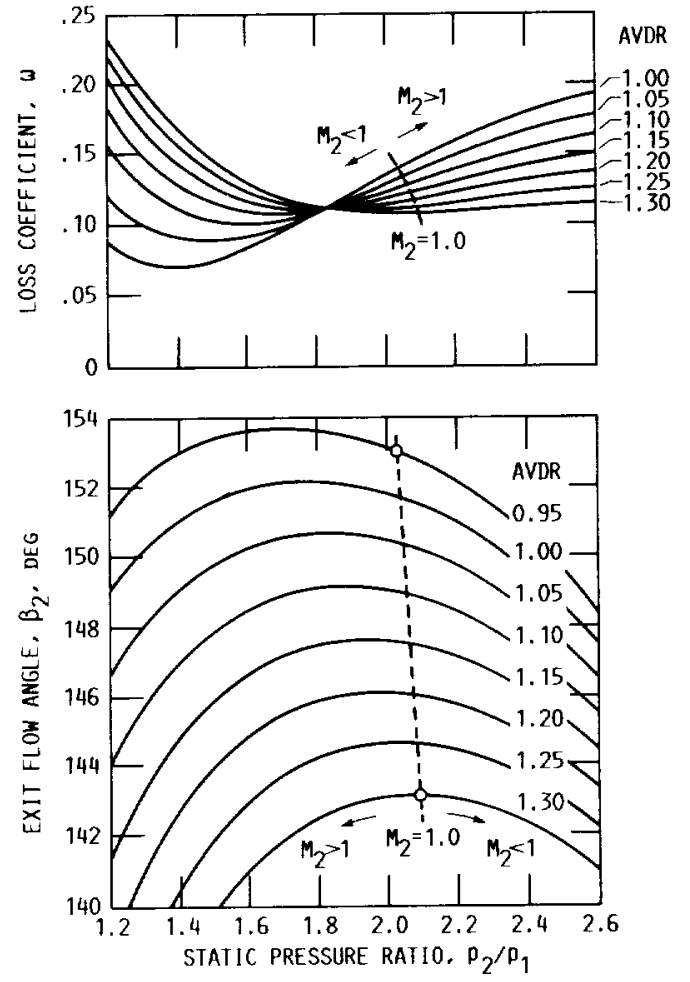

FIGURE 18. - SEMI-EMPIRICAL CURVES FOR AN INLET MACH NUMBER OF $1.61\left(\beta_{1}=\right.$ $147.8^{\circ}$ ) SHOWING THE INFLUENCE OF STATIC PRESSURE RATIO ON THE TOTAL-PRESSURE LOSS COEFFICIENT AND THE EXIT FLOW ANGLE.

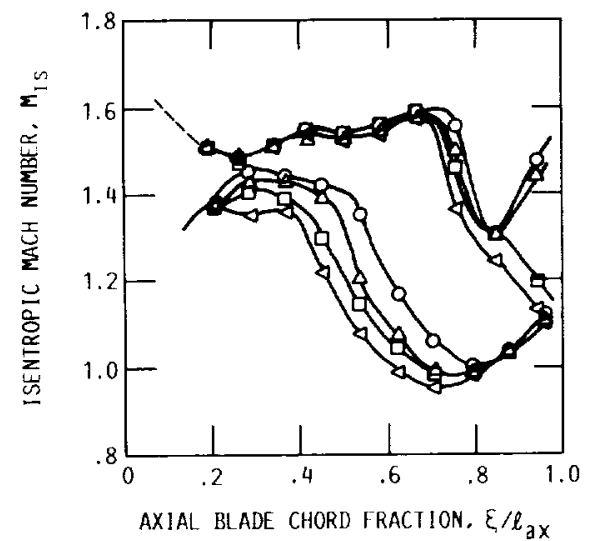

\begin{tabular}{|c|c|c|c|c|c|c|}
\hline & $M_{1}$ & $M_{2}$ & $p_{2} / p_{1}$ & $\begin{array}{c}\beta_{2} \\
\text { DEG }\end{array}$ & $\omega$ & AVDR \\
\hline 0 & 1.58 & 0.93 & 2.12 & 151.2 & 0.144 & 0.99 \\
\hline$\Delta$ & 1.58 & 0.91 & 2.16 & 150.8 & 0.143 & 1.00 \\
\hline$\square$ & 1.59 & 0.93 & 2.18 & 148.0 & 0.123 & 1.12 \\
\hline$\Delta$ & 1.59 & 0.91 & 2.22 & 147.5 & 0.117 & 1.14 \\
\hline
\end{tabular}

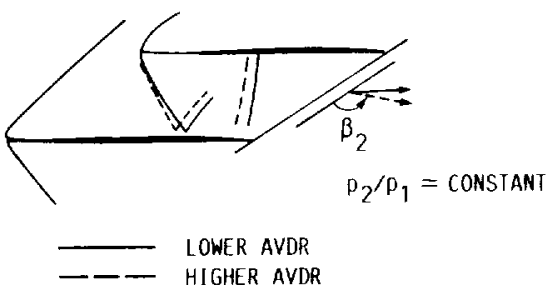

FIGURE 19. - INFLUENCE OF AVDR ON THE BLADE ISENTROPIC MACH NUMBER DISTRIBUTION. FOR A NEARLY CONSIANT BACK PRESSURE AND A NOMINAL INLET MACH NUMBER OF 1.58 $\left(\beta_{1}=147.9^{0}\right)$. 

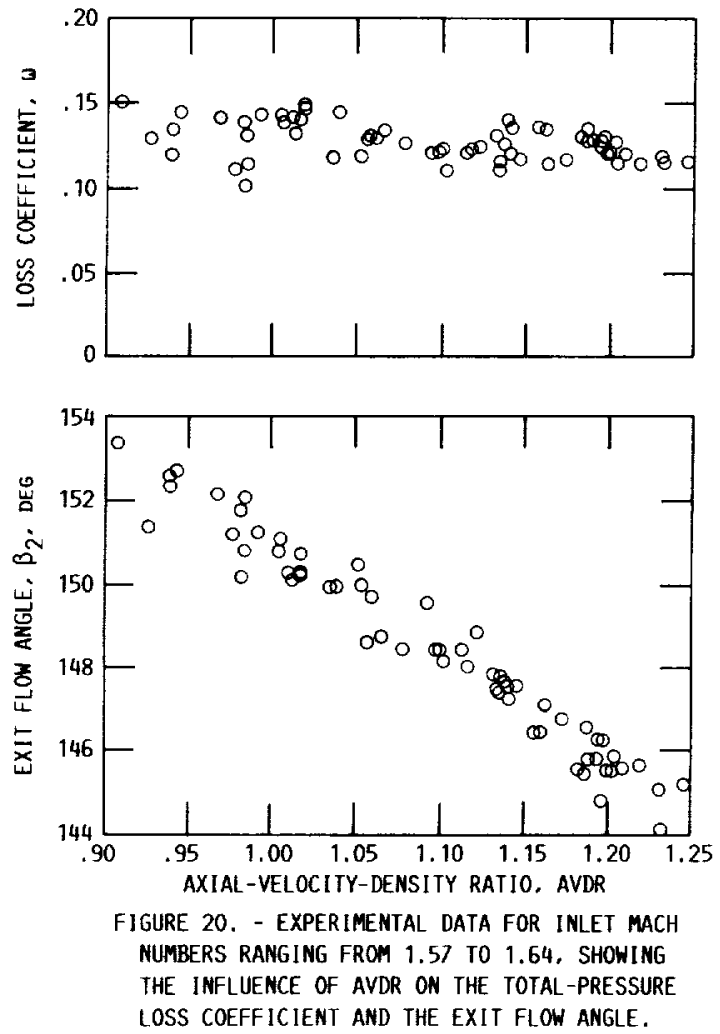
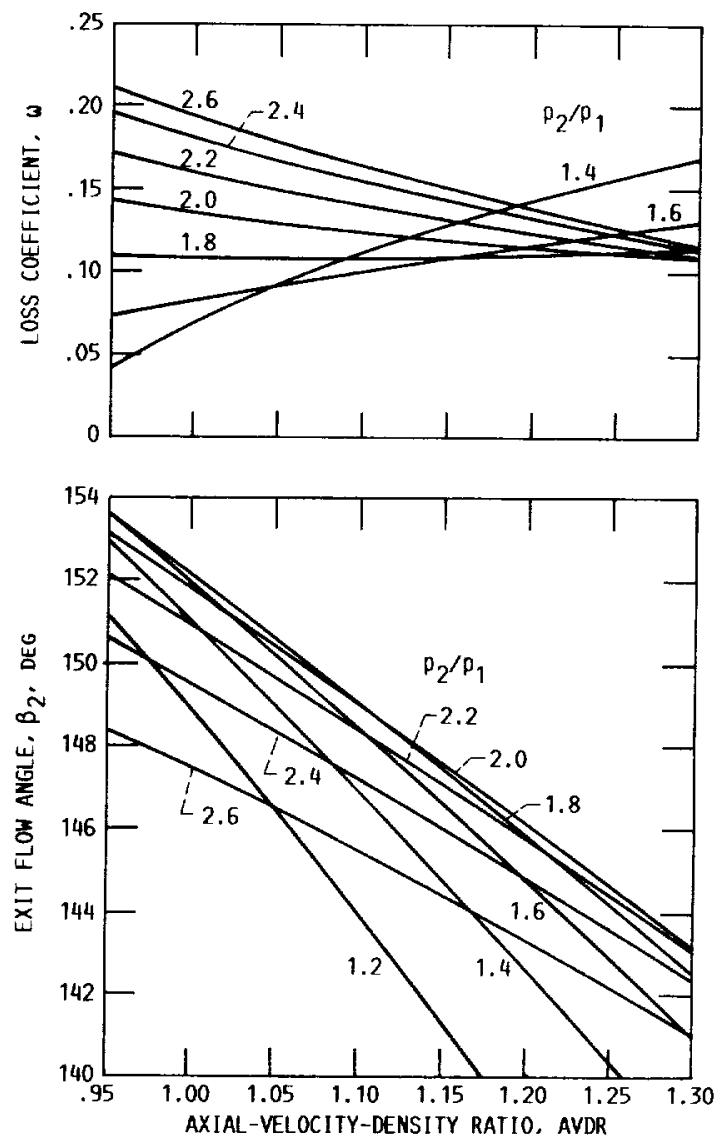

FIGURE 21. - SEMI-EMPIRICAL CURVES FOR AN INLET MACH NUMBER OF $1.61\left(\beta_{1}=147.8^{0}\right)$ SHOWING THE INFLLUENCE OF AVDR ON THE TOTAL-PRESSURE LOSS COEFFICIENT AND THE EXIT FIOW ANGLE. 


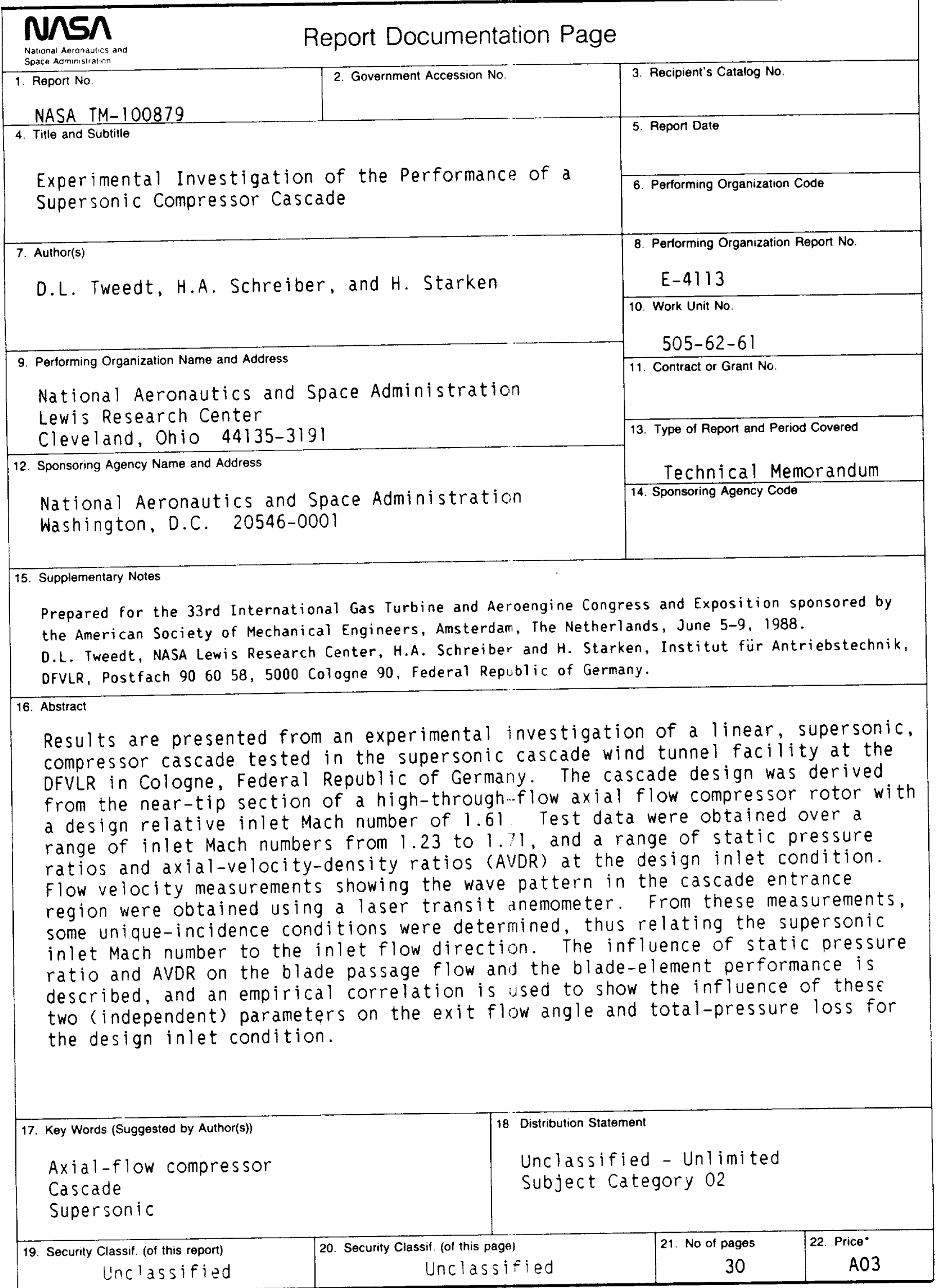


